\title{
Treatment of Helicobacter pylori infection favourably affects gastric mucosal superoxide dismutases
}

\author{
J M Götz, J L Thio, H W Verspaget, G J A Offerhaus, I Biemond, C B H W Lamers, \\ $\mathrm{R}$ A Veenendaal
}

\begin{abstract}
Background and aims-Excessive production of reactive oxygen metabolites (ROMs) by phagocytic cells is thought to contribute to the mucosal pathology of Helicobacter pylori infection. Previously, $H$ pylori infection was shown to have a differential effect on some gastric mucosal scavenger enzymes of ROMs - namely, mitochondrial and cytoplasmic superoxide dismutases - reflected by a large increase in the cytokine inducible manganese superoxide dismutase and a marginal decrease in the constitutive copper/zinc superoxide dismutase. The present study was performed to evaluate whether these altered mucosal superoxide dismutase concentrations and activities in $H$ pylori associated gastritis are reversed to normal by successful treatment of the infection.
\end{abstract}

Patients and methods-In two different treatment groups - namely, omeprazole or ranitidine, in combination with clarithromycin and metronidazole (OME/AB $(n=33)$ and RAN/AB $(n=30)$ ) - manganese superoxide dismutase and copper/zinc superoxide dismutase concentrations were evaluated by enzyme linked immunosorbent assays in homogenates of gastric antrum and corpus biopsy specimens obtained before and eight weeks after successful treatment of $H$ pylori infection. Superoxide dismutase activities in these homogenates were determined spectrophotometrically in eight patients of both groups before and after successful treatment. The concentrations of gastric mucosal superoxide dismutases were also determined in 12 patients with a persistent $H$ pylori infection, with $(n=4)$ or without $(n=8)$ eradication therapy. Infection and eradication of $\boldsymbol{H}$ pylori were confirmed by a combination of culture and histology. Results-Concentrations of manganese superoxide dismutase were significantly lower after than before therapy in antral $(p<0.001$ in both treatment groups) and corpus ( $p<0.001$ in both treatment groups) mucosa. By contrast, copper/zinc superoxide dismutase concentrations were significantly higher $(\mathbf{p}<0.001)$ only in antral mucosa of the OME/AB treated group. Manganese superoxide dismutase activity was significantly lower after than before treatment in antral (OME/AB p<0.01, RAN/AB p<0.001), but not in corpus mucosa. Copper/zinc superoxide dismutase activity was not significantly altered by therapy. In the 12 patients with a persistent $H$ pylori infection no major changes in the gastric mucosal superoxide dismutase concentrations were found.

Conclusions-The raised manganese superoxide dismutase and reduced copper/ zinc superoxide dismutase concentrations and activities in $H$ pylori associated gastritis were reversed towards normal by successful treatment of the infection.

(Gut 1997; 40: 591-596)

Keywords: antioxidants, gastric mucosa, gastritis, Helicobacter pylori, reactive oxygen species, superoxide dismutase.

Helicobacter pylori infection of the gastric mucosa is strongly associated with gastritis and peptic ulcer disease. ${ }^{14}$ Furthermore, long term $H$ pylori associated gastritis is recognised as a causative factor in gastric carcinogenesis. ${ }^{56} \mathrm{As}$ well as via locally acting toxic factors such as cytotoxins, urease, and ammonia, mucosal damage by $H$ pylori infection is also caused by attraction and activation of phagocytes producing large quantities of reactive oxygen metabolites (ROMs), primarily to facilitate killing of microorganisms. ${ }^{79}$ These highly toxic ROMs can also cause damage to cellular components in the host, such as structural and regulatory proteins, lipids, carbohydrates, and DNA. ${ }^{10}$ Excessive ROM production is thought to contribute to various diseases of the gastrointestinal tract, as shown in animal models and human studies, ${ }^{79} 1112$ and has been found in association with $H$ pylori infection. ${ }^{13} 14$

Organisms possess enzymatic as well as nonenzymatic defence mechanisms against the toxicity of ROMs. ${ }^{121516}$ An important scavenging enzyme in the defence against reactive oxygen species, particularly superoxide anion $\left(\mathrm{O}_{2}^{-}\right)$, is superoxide dismutase.${ }^{17}$ In humans it is present in at least two forms cytoplasmic copper/zinc superoxide dismutase and mitochondrial manganese superoxide dismutase. Superoxide dismutases are enzymes that catalyse the dismutation of $\mathrm{O}_{2}^{-}$to hydrogen peroxide, which is decomposed by other enzymes such as catalase and glutathione peroxidase. ${ }^{10}$ Our group recently showed that $H$ pylori induced inflammation of the gastric 
mucosa is accompanied by an increase in manganese superoxide dismutase concentration and activity, both in antral and in corpus mucosa, whereas copper/zinc superoxide dismutase was slightly decreased. ${ }^{18}$ We suggested that the alterations in the manganese superoxide dismutase profile in $H$ pylori associated gastritis are a defensive mechanism against possible intracellular damage by free radicals.

The present study was performed to evaluate the effect of eradication of $H$ pylori on the concentration and activity of superoxide dismutases, in particular the manganese type.

\section{Methods}

PATIENTS AND BIOPSIES

Biopsy material from 63 dyspeptic patients who were $H$ pylori positive was obtained through gastroscopy. Patients who used or had recently used proton pump inhibitors, corticosteroids, non-steroidal anti-inflammatory drugs, bismuth compounds, sucralfate, or antibiotics were excluded. Use of a low dose $\mathrm{H}_{2}$ receptor antagonist was not considered to be a reason for exclusion. At endoscopy two biopsy specimens from the antrum, 3-5 cm proximal to the pylorus, and two from the corpus, about $5 \mathrm{~cm}$ above the junction between antrum and corpus were obtained for histological examination. These specimens were examined in accordance with the guidelines of the updated Sydney system, by an experienced pathologist. ${ }^{19}$ Active (neutrophils) and chronic (mononuclear cells) inflammation were graded on a visual analogue scale and converted to numerical scores (normal $=0$, mild $=1$, moderate $=2$, and severe=3). A single biopsy specimen for $H$ pylori culture was taken from the antrum and was processed as previously described.$^{20} \mathrm{~A}$ further two biopsy specimens of antrum and corpus were used for the determination of the superoxide dismutase concentration and activity.

If culture, or histology, or both were positive for $H$ pylori the patients were treated with a combination regimen of acid inhibitory therapy (omeprazole (20 mg twice a day) in 33 patients, 20 men, 13 women, mean age 53 (range 22-75) years, or ranitidine $(150 \mathrm{mg}$ twice a day or $300 \mathrm{mg}$ four times a day) in 30 patients, 24 men, six women, mean age 47 (range 22-74) years with clarithromycin (500 $\mathrm{mg}$ thrice daily) and metronidazole $(500 \mathrm{mg}$ thrice daily) for 14 days, the second only in $50 \%$ of the omeprazole treated patients. These combinations are referred to as $\mathrm{OME} / \mathrm{AB}$ and RAN/AB respectively. Successful $H$ pylori treatment was defined as a negative culture of the antrum biopsy sample and a negative histology, both in the antrum and corpus, eight weeks after the end of therapy. In another four patients (two men, two women, mean age 44 (range 24-60) years) who were treated with $\mathrm{OME} / \mathrm{AB}$ (double) therapy, $H$ pylori was not eradicated. Furthermore, from eight $H$ pylori positive patients (four men, four women, mean age 51 (range 36-67) years), biopsy specimens were available at two time points with a mean interval of 9.5 months (range 2-39 months), without an intermediate $H$ pylori eradication treatment and consequently no change in the $H$ pylori status. In these biopsy specimens the gastric mucosal superoxide dismutase concentrations were determined as well.

\section{TISSUE EXTRACTION}

Biopsy specimens for superoxide dismutase measurements were combined for each localisation, weighed, and homogenised on ice with a Potter S (B Braun) in $300 \mu l$ phosphate buffered saline (PBS) containing 0.05\% Tween 20 (PBST). The final concentration of the biopsy specimens was $1 \mathrm{mg}$ biopsy tissue per $100 \mu l$ PBST. Protein concentration of the homogenates was determined by the method of Lowry et $a .^{21}$

\section{ELISA FOR COPPER/ZINC SUPEROXIDE}

DISMUTASE

The copper/zinc superoxide dismutase concentration in the tissue homogenates was determined by an adapted enzyme linked immunosorbent assay (ELISA). ${ }^{1822}$ Briefly, each well of a flat bottomed polystyrene microtitre plate (Dynatech Laboratories, USA; M129A) was coated with $100 \mu l$ antibody solution $(10 \mu \mathrm{g} / \mathrm{ml}$ goat $\alpha$-copper/zinc superoxide dismutase in carbonate buffer, $\mathrm{pH}$ $9 \cdot 6$ ), overnight at $4^{\circ} \mathrm{C}$. A second coating followed with a $0.2 \%$ gelatin solution for one hour. The plates were washed and each homogenate, $100 \mu$ l diluted $1: 100$ in PBST/ gelatin $(0.05 \%$ Tween 20$)$, was added to each well in duplicate. After two hours of incubation and washing, $100 \mu l$ rabbit $\alpha$-copper/zinc superoxide dismutase serum diluted 1:2500 was added to the wells. The plates were incubated for 1.5 hours and washed again. Next, the wells were incubated for one hour with $100 \mu l$ preabsorbed goat $\alpha$-rabbit peroxidase (Dakopatts P448) diluted 1:5000. Bound antibodies were detected using $100 \mu \mathrm{l}$ of a solution of $40 \mathrm{mg}$ orthophenylenediamine and $40 \mu \mathrm{H} \mathrm{H}_{2} \mathrm{O}_{2}$ in $100 \mathrm{ml}$ citric acid/phosphate buffer, $\mathrm{pH} 5 \cdot 0$. The incubation time was 20 minutes for each well, the reaction being stopped with $50 \mu \mathrm{l} 2.5 \mathrm{M}$ sulphuric acid. The optical density was read at $492 \mathrm{~nm}$ on a Titertek Multiscan (Flow Laboratories, UK) plate reader. The copper/zinc superoxide dismutase concentration was calculated from a calibration curve based on 10 standards between 1.25 and $40 \mathrm{ng} / \mathrm{ml}$ human recombinant copper/zinc superoxide dismutase and expressed per $\mathrm{mg}$ protein of the homogenate.

ELISA FOR MANGANESE SUPEROXIDE DISMUTASE This procedure closely resembles the ELISA for copper/zinc superoxide dismutase. The microtitre plates were coated overnight with $10 \mu \mathrm{g} / \mathrm{ml}$ rabbit $\alpha$-manganese superoxide dismutase in carbonate buffer. The homogenates were diluted 1:50 in PBST and 
incubated for two hours. After washing, 1:250 rabbit $\alpha$-manganese superoxide dismutase peroxidase was added to each well. After one hour bound antibodies were detected as described for copper/zinc superoxide dismutase. The standard used in this assay was human recombinant manganese superoxide dismutase.

Human recombinant manganese superoxide dismutase and copper/zinc superoxide dismutase were kindly provided by $\mathrm{Dr} \mathrm{Z}$ Yavin from the Kyriat Weizmann Institute, Rehovot, Israel.

\section{SUPEROXIDE DISMUTASE ACTIVITY} MEASUREMENT

Superoxide dismutase activity was measured in tissue homogenates of biopsy specimens

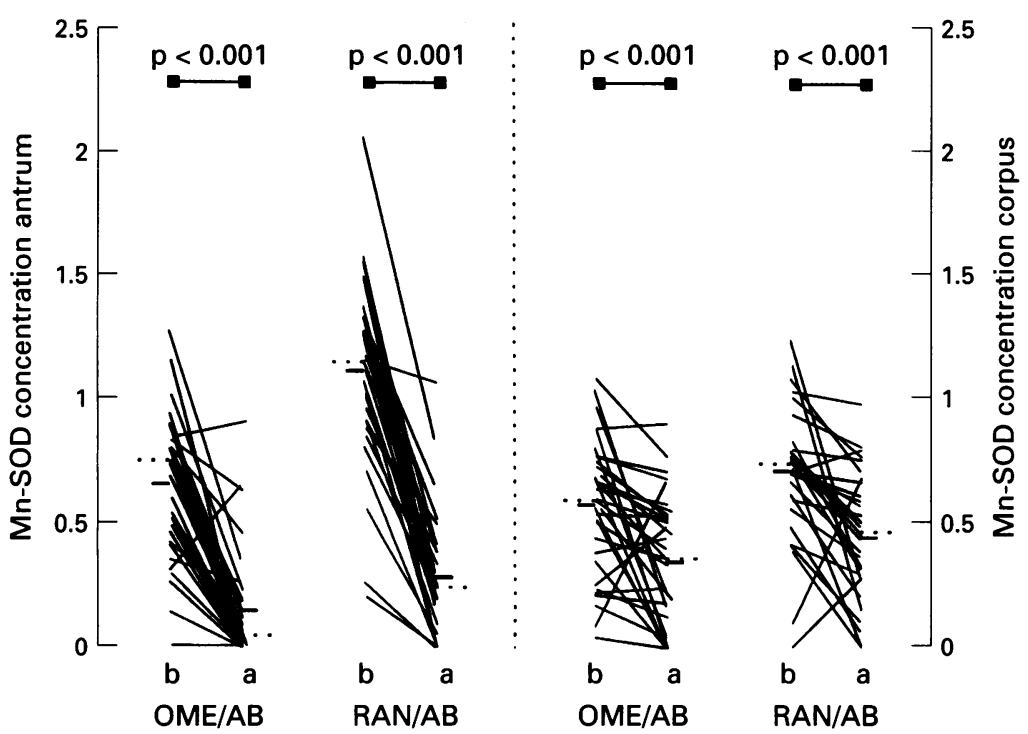

Figure 1: Effect of eradication of $\mathrm{H}$ pylori by omeprazole based therapy $(O M E / A B, n=33)$ and by ranitidine based therapy $(R A N / A B, n=30)$ on manganese superoxide dismutase (Mn-SOD) concentrations in antral and corpus biopsy specimens. Concentrations in $\mu \mathrm{g} / \mathrm{mg}$ protein (SEM) (paired analysis). Mean ( $(-)$ and median ( $\cdots$ ) concentrations are indicated. (a) After treatment, (b) before treatment.
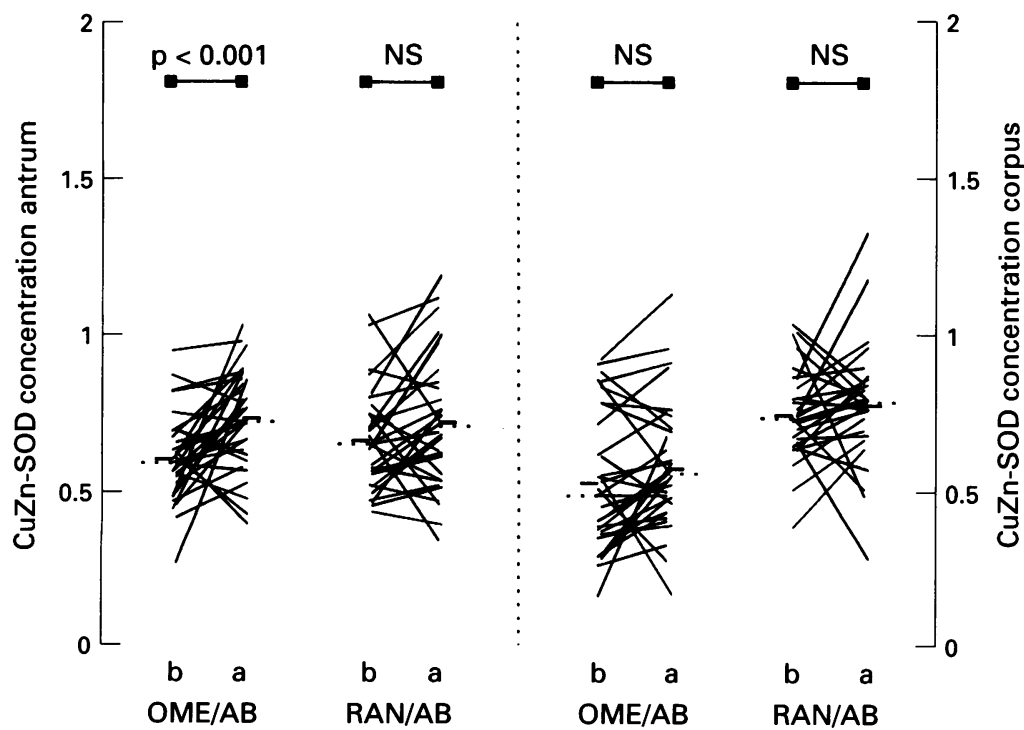

Figure 2: Effect of eradication of $\mathrm{H}$ pylori by omeprazole based therapy (OME/AB, $n=33$ ) and by ranitidine based therapy $(R A N / A B, n=30)$ on copper/zinc superoxide dismutase (CuZn-SOD) concentrations in antral and corpus biopsy specimens. Concentrations in $\mu g / m g$ protein (SEM) (paired analysis). Mean (-) and median ( $\cdots$ ) concentrations are indicated. (a) After treatment, (b) before treatment. obtained before and after treatment from eight patients of both treatment groups, using the xanthine/xanthine oxidase/cytochrome c method..$^{18}$ In the presence of xanthine, xanthine oxidase produces $\mathrm{O}_{2}^{-}$, which is detected by its ability to reduce cytochrome c. This reduction will be inhibited by superoxide dismutase, through competition with cytochrome $\mathrm{c}$ for the dismutation of $\mathrm{O}_{2}^{+}$. In this assay, $80 \mu l$ homogenate was added to $890 \mu l$ phosphate buffer, $\mathrm{pH} 7 \cdot 8$. By adding $10 \mu \mathrm{l}$ xanthine ( $5 \mathrm{mg}$ in $6.57 \mathrm{ml} 0.05 \mathrm{M} \mathrm{KOH}$ ), xanthine oxidase $(15 \mu \mathrm{l}$ in $435 \mu \mathrm{l}$ phosphate buffer), and cytochrome c (25 mg in $2.02 \mathrm{ml}$ phosphate buffer) the reaction started as described above. The reduction of cytochrome c was followed in a spectrophotometer at $550 \mathrm{~nm}$. To provide an estimate of total superoxide dismutase activity in each homogenate a calibration curve based on six standards between 25 and $250 \mathrm{ng}$ superoxide dismutase was used. Manganese superoxide dismutase activity was determined using the same method, but in the presence of $1 \mathrm{mM}$ potassium cyanide which inhibits copper/zinc superoxide dismutase by $\geq 90 \%$. Copper/zinc superoxide dismutase was thus estimated by subtraction of manganese superoxide dismutase from total superoxide dismutase activity. The activity is expressed in units/mg protein, in which one unit is the superoxide dismutase activity which causes $50 \%$ inhibition of the reaction rate in the absence of superoxide dismutase. For copper/zinc superoxide dismutase one unit corresponds to $180 \mathrm{ng}$ active human recombinant copper/zinc superoxide dismutase, whereas one unit manganese superoxide dismutase corresponds to $225 \mathrm{ng}$ active human recombinant manganese superoxide dismutase.

\section{STATISTICAL ANALYSIS}

The significance of the differences between the pretreatment and post-treatment superoxide dismutase concentrations and activities in the biopsy homogenates was assessed by paired Student's $t$ test.

\section{Results}

The two treatment groups were analysed separately to evaluate whether $H$ pylori therapy based on the proton pump inhibitor omeprazole or the $\mathrm{H}_{2}$ receptor antagonist ranitidine had similar effects on the superoxide dismutase concentrations in the gastric mucosa and to exclude concealment of different findings. In addition, patients in the RAN/AB group were found to have significantly higher $(p<0.02-p<0.001)$ concentrations of manganese superoxide dismutase in the antral mucosa and copper/zinc superoxide dismutase in the corpus mucosa compared with the $\mathrm{OME} / \mathrm{AB}$ group before treatment, which remained significant even after treatment (see data below and Figs 1 and 2).

After therapy manganese superoxide dismutase concentrations were significantly lower (all $\mathrm{p}<0.001$ ) compared with before therapy in 
both treatment groups in antral (OME/AB $0.14(0.04) \quad v \quad 0.65(0.05) ; \mathrm{RAN} / \mathrm{AB} \quad 0.29$ $(0.05)$ v $1.10(0.07))$ as well as corpus mucosa (OME/AB 0.34 (0.05) v 0.57 (0.05); RAN/AB $0.45(0.05) v 0.71(0.05))$, as illustrated in Fig 1. By contrast, copper/zinc superoxide dismutase concentrations were higher after than before treatment, although only significantly in antral mucosa of the OME/AB group $(0.73(0.03) v 0.60(0.02), \mathrm{p}<0.001$; RAN/AB $0.72(0.04) v 0.66(0.03)$, NS). In corpus mucosa no significant change in the copper/zinc superoxide dismutase antigen concentration was found compared with before treatment (OME/AB 0.58 (0.04) v 0.53(0.04); $\begin{array}{lllllll}\mathrm{RAN} / \mathrm{AB} & 0.78 & (0.04) & v & 0.75 & (0.03) & \text { re- }\end{array}$ spectively; Fig 2).

TABLE I Manganese superoxide dismutase (Mn-SOD) and copper/zinc superoxide dismutase (CuZn-SOD) activity in gastric mucosal biopsy specimens of $\mathrm{H}$ pylori positive patients before and after successful omeprazole based (OME/AB) and ranitidine based eradication therapy $(R A N / A B)$

\begin{tabular}{|c|c|c|c|c|c|c|}
\hline & \multicolumn{3}{|c|}{$M n-S O D(n=8)$} & \multicolumn{3}{|c|}{$C u Z n-S O D(n=8)$} \\
\hline & Before & After & $p$ Value & Before & After & $p$ Value \\
\hline $\begin{array}{r}\text { OME/AB: } \\
\text { Antrum } \\
\text { Corpus } \\
\text { RAN/AB: }\end{array}$ & $\begin{array}{l}4.76(0.91) \\
2.87(0.74)\end{array}$ & $\begin{array}{l}0.94(0.58) \\
2.33(0.64)\end{array}$ & $\begin{array}{l}<0.01 \\
\text { NS }\end{array}$ & $\begin{array}{l}4 \cdot 65(0.50) \\
5 \cdot 14(0.76)\end{array}$ & $\begin{array}{l}6.59(0.85) \\
5.27(0.65)\end{array}$ & $\begin{array}{l}\text { NS } \\
\text { NS }\end{array}$ \\
\hline $\begin{array}{l}\text { Antrum } \\
\text { Corpus }\end{array}$ & $\begin{array}{l}3.17(0.55) \\
2.34(0.30)\end{array}$ & $\begin{array}{l}0.96(0.35) \\
1.44(0.37)\end{array}$ & $\begin{array}{l}\leq 0.001 \\
\text { NS }\end{array}$ & $\begin{array}{l}5.41(0.61) \\
5.23(0.70)\end{array}$ & $\begin{array}{l}5.91(0.68) \\
5.72(0.55)\end{array}$ & $\begin{array}{l}\text { NS } \\
\text { NS }\end{array}$ \\
\hline
\end{tabular}

Activity is expressed in units/mg protein (SEM) (paired analysis).

TABLE II Active (neutrophils) and chronic (mononuclear cells) inflammation scores based on the updated Sydney system for the histological evaluation of gastric mucosal biopsy specimens of $\mathrm{H}$ pylori positive patients before and after successful omeprazole based eradication treatment (OME/AB, $n=33$ ) or ranitidine based eradication therapy ( $R A N)$ $A B, n=30$ )

\begin{tabular}{|c|c|c|c|c|c|c|}
\hline & \multicolumn{3}{|c|}{ Active inflammation } & \multicolumn{3}{|c|}{ Chronic inflammation } \\
\hline & Before & After & p Value & Before & After & p Value \\
\hline \multicolumn{7}{|l|}{ OME/AB: } \\
\hline Antrum & $1 \cdot 2(0 \cdot 1)$ & $0 \cdot 1(0 \cdot 1)$ & $<0.001$ & $1.9(0.1)$ & $1 \cdot 2(0 \cdot 1)$ & $<0.001$ \\
\hline Corpus & $0.5(0.1)$ & $0.1(0.1)$ & 0.002 & $1.5(0.1)$ & $1.0(0.1)$ & $<0.001$ \\
\hline \multicolumn{7}{|l|}{ RAN/AB: } \\
\hline Antrum & $1 \cdot 0(0 \cdot 1)$ & $0(0)$ & $<0.001$ & $1 \cdot 7(0 \cdot 1)$ & $1.0(0)$ & $<0.001$ \\
\hline Corpus & $0.4(0.1)$ & $0(0)$ & $<0.001$ & $1 \cdot 2(0 \cdot 1)$ & $1.0(0)$ & $<0.02$ \\
\hline
\end{tabular}

Scores are means (SEM).

Updated Sydney system ${ }^{19}$ score grading: normal $=0 ;$ mild $=1$; moderate $=2 ;$ and severe $=3$.

TABLE III Manganese superoxide dismutase (Mn-SOD) and copper/zinc superoxide dismutase (CuZn-SOD) concentrations in gastric mucosal biopsy specimens of $\mathrm{H}$ pylori positive patients before and after unsuccessful treatment (no eradication of $\mathrm{H}$ pylori)

\begin{tabular}{|c|c|c|c|c|c|c|}
\hline & \multicolumn{3}{|c|}{$M n-S O D(n=4)$} & \multicolumn{3}{|c|}{$C u Z n-S O D(n=4)$} \\
\hline & Before & After & p Value & Before & After & $p$ Value \\
\hline $\begin{array}{l}\text { Antrum } \\
\text { Corpus }\end{array}$ & $\begin{array}{l}0.76(0.05) \\
0.58(0.19)\end{array}$ & $\begin{array}{l}0.82(0.08) \\
0.69(0.09)\end{array}$ & $\begin{array}{l}\text { NS } \\
\text { NS }\end{array}$ & $\begin{array}{l}0.61(0.07) \\
0.50(0.16)\end{array}$ & $\begin{array}{l}0.72(0.09) \\
0.54(0.11)\end{array}$ & $\begin{array}{l}\text { NS } \\
\text { NS }\end{array}$ \\
\hline
\end{tabular}

Results expressed as $\mu \mathrm{g} / \mathrm{mg}$ protein (SEM) (paired analysis).

TABLE IV Manganese superoxide dismutase (Mn-SOD) and copper/zinc superoxide dismutase (CuZn-SOD) concentrations in gastric mucosal biopsy specimens of consistently $\mathrm{H}$ pylori positive patients obtained on two separate occasions with no intermediate $\mathrm{H}$ pylori eradication therapy

\begin{tabular}{|c|c|c|c|c|c|c|}
\hline & \multicolumn{3}{|c|}{$M n-S O D(n=8)$} & \multicolumn{3}{|c|}{$C u Z n-S O D(n=8)$} \\
\hline & First & Second & p Value & First & Second & p Value \\
\hline $\begin{array}{l}\text { Antrum } \\
\text { Corpus }\end{array}$ & $\begin{array}{l}0.89(0.06) \\
0.65(0.09)\end{array}$ & $\begin{array}{l}0.87(0.10) \\
0.80(0.07)\end{array}$ & $\begin{array}{l}\text { NS } \\
\text { NS }\end{array}$ & $\begin{array}{l}0.67(0.09) \\
0.58(0.06)\end{array}$ & $\begin{array}{l}0.61(0.05) \\
0.67(0.06)\end{array}$ & $\begin{array}{l}\text { NS } \\
<0.01\end{array}$ \\
\hline
\end{tabular}

Results expressed as $\mu \mathrm{g} / \mathrm{mg}$ protein (SEM) (paired analysis)

Mean (range) interval between measurements $9 \cdot 5$ (2-39) months.
Manganese superoxide dismutase activity in both treatment groups was also significantly lower $(p<0.01)$ after than before treatment in antral but not in corpus mucosa, whereas copper/zinc superoxide dismutase activity was not significantly altered by therapy, neither in antral nor in corpus mucosa (Table I).

Histological evaluation of the gastric mucosal biopsy specimens disclosed that the active inflammation was almost completely resolved after treatment in both treatment groups, whereas the chronic inflammation persisted although significantly reduced in both antrum and corpus (Table II).

In the four patients in whom $H$ pylori was not eradicated after therapy no major alterations in the gastric mucosal superoxide dismutase concentrations were found (Table III). Similarly, in the eight consistently $H$ pylori positive patients on two separate occasions, without intermediate eradication treatment, no significant changes in superoxide dismutase concentrations were found, except for copper/ zinc superoxide dismutase in corpus mucosa (Table IV). Particularly, manganese superoxide dismutase concentrations remained high or showed a tendency to increase further in both groups.

\section{Discussion}

Oxygen radicals are molecules with one or two unpaired electrons in their outer orbital. Some examples are the superoxide anion $\left(\mathrm{O}_{2}^{-}\right)$and the hydroxyl radical ( $\mathrm{OH})$. The superoxide radical is the primary product of an activated NADPH oxidase system in the membrane of inflammatory cells, such as neutrophils and macrophages. The free radicals attack lipid components of cell membranes, proteins, and nucleic acids of microorganisms, but possibly also of the host..$^{7-10} 12151623$ The most important enzymatic antioxidants are superoxide dismutase, catalase, and glutathione reductase. ${ }^{81024}$ In humans, at least two forms of superoxide dismutase are known, a constitutive cytoplasmic form (copper/zinc superoxide dismutase), and an inducible mitochondrial form (manganese superoxide dismutase). ${ }^{23} H$ pylori has been shown to possess an iron containing superoxide dismutase, ${ }^{25}$ which does not cross react with the antibodies against the human superoxide dismutases in our ELISAs. ${ }^{18}$

Previously, we have shown that in $H$ pylori associated gastritis an increase in concentration and activity of manganese superoxide dismutase exists, as well as a minor decrease in copper/zinc superoxide dismutase, which might be regarded as a response by the host to minimise gastric mucosal damage due to free radicals produced in response to $H$ pylori infection. ${ }^{18}$ In the present study we assessed the effect of eradication of $H$ pylori on the gastric concentrations and activities of mucosal superoxide dismutase in biopsy specimens from the gastric antrum and corpus, in patients who were treated with either an omeprazole based (OME/AB) or a ranitidine based (RAN/ AB) $H$ pylori eradication treatment. Although 
there were pretreatment and post-treatment differences in the gastric mucosal superoxide dismutase concentrations between the two treatment groups, which might be related to differences in the age and sex distribution, we found with both therapies that the increased concentration and activity of manganese superoxide dismutase was reversed by successful treatment of the $H$ pylori infection. These concentrations of gastric mucosal manganese superoxide dismutase became comparable with those of patients without an $H$ pylori infection and with a histologically normal gastric mucosa, as described previously. ${ }^{18}$ The finding of a persistently high manganese superoxide dismutase concentration in the gastric mucosa of patients when $H$ pylori eradication either failed or was not attempted, indicates that normalisation of this variable is directly related to the elimination of the organism. Conceivably, this is a result of the disappearance of the antigenic stimulus, such as $H$ pylori derived neutrophil activating and cytotoxic factors, thus leading to a disappearance of active inflammation and subsequently to decreasing concentrations of tumour necrosis factor- $\alpha$ and interleukins, ${ }^{26}$ particularly as these compounds have been shown to increase manganese superoxide dismutase expression. ${ }^{27}$ The manganese superoxide dismutase activity in the antrum was lower after than before therapy in both treatment groups, but did not change in corpus mucosa. We ascribe this finding to the fact that $H$ pylori associated gastritis is antrum predominant, with less active inflammation in the corpus.

Furthermore, no major changes occurred in the copper/zinc superoxide dismutase antigen concentration and activity, neither in antral nor in corpus mucosa, after the eradication of $H$ pylori. This finding is not surprising as the constitutive copper/zinc superoxide dismutase is not inducible by cytokines, and no impressive alterations in this enzyme were previously found in $H$ pylori associated gastritis. ${ }^{18}$ Moreover, although eradication of $H$ pylori was achieved, complete histological normalisation during this relatively short follow up was not obtained, as illustrated by the decreased but not fully resolved chronic inflammation. Perhaps only then the copper/ zinc superoxide dismutase concentrations in the gastric mucosa might return to the previously described higher values in patients without an $H$ pylori infection. ${ }^{18}$

$H$ pylori has been recognised as a causal agent in gastric carcinogenesis, and damage to DNA by free radicals in chronic active gastritis might be an important link in this connection. ${ }^{1023}$ Furthermore, it has been established that concentrations of manganese superoxide dismutase are raised in several malignant diseases of the digestive tract, in both serum and tissue homogenates. ${ }^{28} 29$ These raised concentrations in colorectal carcinoma were even found to be related to the clinical outcome of the patients. ${ }^{29}$ We showed in the present study that the upregulation of the free radical scavenging system related to man- ganese superoxide dismutase is reversed by successful treatment of $H$ pylori, possibly reflecting a diminishing free radical contribution in the pathological process. Similarly, we have previously shown a (pre)malignant profile in gastric mucosal plasminogen activators in $H$ pylori infection that approached normal values after successful treatment of the infection. ${ }^{30} 31$ Others have shown that the increased gastric epithelial cell proliferation in $H$ pylori associated gastritis is reduced after successful treatment. ${ }^{32}{ }^{33}$ Furthermore, in accord with our findings $H$ pylori eradication restores decreased vitamin $\mathrm{C}$ concentrations in gastric juice. ${ }^{34}{ }^{35}$ Whether all these effects will ultimately result in a decreased risk for gastric cancer, however, remains to be established.

We thank W van Duijn, G Kuiper, and MAC Mieremet-Ooms for their technical expertise.

1 Warren JR, Marshall BJ. Unidentified curved bacilli on gastric epithelium in active chronic gastritis. Lancet 1983; i: $1273-5$.

2 Blaser MJ. Hypotheses on the pathogenesis and natural history of Helicobacter pylori induced inflammation. Gastroenterology 1992; 102: 720-7.

3 Taylor DN, Blaser MJ. The epidemiology of Helicobacter pylori infection. Epidemiol Rev 1991; 13: 42-59.

$4 \mathrm{NIH}$ consensus development panel on Helicobacter pylori in peptic ulcer disease. Helicobacter pylori in peptic ulcer in peptic ulcer disease. Helicobact

5 Correa $P$. Human gastric carcinogenesis: a multistep and multifactorial process. Cancer Res 1992; 52: 6735-40.

6 Anonymous. Schistosomes, liver flukes, and Helicobacter pylori. IARC working group on the evaluation of carcinogenic risks to humans. IARC Monogr Eval Carcinog Risks Hum 1994; 61: 1-241.

7 Weiss SJ. Tissue destruction by neutrophils. N Engl f Med 1989; 320: 365-76

8 Halliwell B, Gutteridge JMC, Cross CE. Free radicals, antioxidants, and human disease: where are we now? $f$ Clin Lab Med 1992; 119: 598-620.

9 Davies GR, Rampton DS. Helicobacter pylori, free radicals, and gastro-duodenal disease. Eur $\mathcal{f}$ Gastroenterol Hepatol 1994; 6: $1-10$.

10 Cheeseman KH, Slater TF. An introduction to free radical biochemistry. Br Med Bull 1993; 49: 481-93.

11 Niida $H$, Okada $M$, Takeuchi $K$, Okabe S. A new model of duodenal ulcers induced in rats by diethyldithiocarbamate, a superoxide dismutase inhibitor. Scand f Gastroenterol 1989; 24 (suppl 162): 116-9.

12 Verspaget HW, Mulder TPJ, van der Sluys Veer A, Peña AS, Lamers CBHW. Reactive oxygen metabolites and colitis; a disturbed balance between damage and protection. Scand $\mathcal{F}$ Gastroenterol 1991; 26 (suppl 188): 44-51.

13 Nielsen H, Andersen LP. Activation of human phagocyte oxidative metabolism by Helicobacter pylori. Gastroenterology 1992; 103: 1747-53.

14 Davies GR, Simmonds NJ, Stevens TRJ, Sheaff MT, Banatvala N, Laurenson IF, et al. Helicobacter pylori stimulates antral mucosal reactive oxygen metabolite production in vivo. Gut 1994; 35: 179-85.

15 de Groot $H$. Reactive oxygen species in tissue injury. Hepatogastroenterology 1994; 41: 328-32.

16 Smith SM, Kvietys PR. Gastric ulcers: role of oxygen radicals. Crit Care Med 1988; 16: 892-8.

17 Ogino K, Oka S, Okazaki Y, Takemoto T. Gastric mucosal protection and superoxide dismutase. $\mathcal{f}$ Clin Gastroenterol 1988; 10 (suppl 1): S129-32.

18 Götz JM, van Kan CI, Verspaget HW, Biemond I, Lamers CBHW, Veenendaal RA. Gastric mucosal superoxide dismutases in Helicobacter pylori infection. Gut 1996; 38: 502-6.

19 Dixon MF, Genta RM, Yardley JH, Correa P. Classification and grading of gastritis. The updated Sydney system. Am and grading of gastritis. The updathol 1996; 20: 1161-81.

20 Veenendaal RA, Lichtendahl-Bernards AT, Peña AS, Endtz HPh, van Boven CPA, Lamers CBHW. Effect of $\mathrm{HPh}$, van Boven CPA, Lamers CBHW. Effect of transport medium and transportation time on culture of
Helicobacter pylori from gastric biopsy specimens. $\mathcal{F}$ Clin

21 Lowry OH, Rosebrough NJ, Farr AL, Randall RJ. Protein measurements with the Folin phenol reagent. $\mathcal{f}$ Biol Chem 1951; 193: 265-75.

22 Mulder TPJ, Verspaget HW, Janssens AR, De Bruin PAF, Peña AS, Lamers CBHW. Decrease in two intestinal copper/zinc containing proteins with antioxidant function in inflammatory bowel disease. Gut 1991; 32: 1146-50.

3 Beyer W, Imlay J, Fridovich I. Superoxide dismutases. Prog Nucleic Acid Res Mol Biol 1991; 40: 221-53.

24 Kozol R, Kopatzis A, Fligiel SEG, Czanko R, Callewaert D. Neutrophil-mediated injury to gastric mucosal surface cells. Dig Dis Sci 1994; 34: 138-44. 
25 Spiegelhalder C, Gerstenecker B, Kersten A, Schiltz E Kist $M$. Purification of Helicobacter pylori superoxide dismutase and cloning and sequencing of the gene. Infect Immun 1993; 61: 5315-25.

26 Michetti P, Wadström T, Kraehenbuhl J-P, Lee A Kreiss C, Blum AI Frontiers in Helicobacter pylori research: pathogenesis, host response, development, and new therapeutic approaches. Eur $\mathcal{f}$ Gastroenterol Hepatol 1996; 8: 717-22.

27 Visner GA, Dougall WC, Wilson JM, Burr IA, Nick HS. Regulation of manganese superoxide dismutase by factor. 7 Biol Chem 1990; 265: 2856-64.

28 Kawaguchi T, Suzuki KC, Matsuda Y, Nishiura T, Uda T, Ono $M$, et al. Serum manganese superoxide dismutase: normal values and increased levels in patients with acute myocardial infarction and several malignant diseases determined by an enzyme-linked immunosorbent assay using a monoclonal antibody. F Immunol Methods 1990; 127: 249-54

29 Janssen AML, Bosman CB, Sier CFM, Griffioen G, Lamers CBHW, Verspaget HW. Levels and relation with clinical outcome of superoxide dismutases in colorectal neoplasia. Proc Am Assoc Cancer Res 1996; 37: 194.
30 Götz JM, Vergouwe Y, Verspaget HW, Biemond I, Sier CFM, Lamers CBHW, et al. Gastric mucosal plasminogen activators in Helicobacter pylori infection. Dig Dis Sci 1996; 41: 1577-82.

31 Götz JM, Ravensbergen JW, Verspaget HW, Biemond I, Sier CFM, Offerhaus GJA, et al. The effect of treatment of Helicobacter pylori on gastric mucosal plasminogen activators. Fibrinolysis 1996; 10 (suppl 2): 85-9.

32 Alam K, Arlow FL, Ma CK, Schubert TT. Decrease in ornithine decarboxylase activity after eradication of ornithine decarboxylase activity after eradication of 888-93.

33 Lynch DAF, Mapstone NP, Clarke AMT, Sobala GM Jackson P, Morrison L, et al. Cell proliferation in Helicobacter pylori associated gastritis and the effect of eradication therapy. Gut 1995; 36: 346-50.

34 Baneriee S, Hawksby C, Miller S, Dahill S, Beattie AD, McColl KEL. Effect of Helicobacter pylori and its eradication on gastric juice ascorbic acid. Gut 1994; 35 317-22.

35 Rokkas T, Papatheodorou G, Karameris A, Mavrogeorgis A, Kalogeropoulos N, Giannikos N. Helicobacter pylori infection and gastric juice vitamin C levels; impact of eradication. Dig Dis Sci 1995; 40: 615-21. 